\title{
Power-laws in art
}

\author{
Federico Etro $^{\mathrm{a}, *}$, Elena Stepanova ${ }^{\mathrm{b}}$ \\ a Department of Economics, Cá Foscari University, Venice, 30124, Italy \\ b Sant'Anna School of Advanced Studies, Pisa, 56127, Italy
}

\section{A R T I C L E I N F O}

\section{Article history:}

Received 15 January 2018

Available online $\mathrm{xxxx}$

\section{JEL classification:}

C23

Z11

Keywords:

Power laws

Art prices

Talent distribution

Scale-free networks

\section{A B S T R A C T}

We provide evidence of a cubic law of art prices that hints to a general pattern for the distribution of artistic talent. The persistence across heterogeneous markets from historical ones to contemporary art auctions of a power law in the distribution of the average price per artist suggests the possibility of a universal law for talent distribution. We explore scalefree networks of teacher-students to investigate the diffusion of talent over time.

(c) 2018 Elsevier B.V. All rights reserved.

Power-law distributions characterize many natural and social phenomena, including indirect measures of scientific talent (citations), managerial talent (compensations) and earning ability (Pareto law on income distribution) [1,2]. Based on art historical research, we show evidence of a power-law tail in the distribution of artistic talent, which persists over centuries. We measure the talent of artists with the average price of their artworks, obtained for the primary market of Renaissance Italy up to the 1500s and for the secondary markets of Amsterdam during the 1600s and Paris and London between the 1700 s and the 1800s, as well as for the global contemporary art market from worldwide auctions of the period 1985-2016. We uncover an approximately cubic law. Beside its relevance for understanding the distribution and diffusion of human talent, such a finding introduces a scientific approach to questions addressed qualitatively in art history, with rare recent exceptions [3,4].

A measure of talent of professional artists as perceived at the time of its expression is given by the price of artworks when these are traded in a primary market with competition between buyers: this is definitely the case for the tail of the distribution since high talent is scarce and allows the artist-monopolists to extract the expected surplus created by their works. Similarly, in a competitive secondary market, prices of unique objects should reflect the (maximum) willingness to pay on the demand side [4]. Therefore, we interpret the average price of the works of artists as a monetary measure of their talent (or success recognized in a given historical context). We have collected data on the price of paintings from art historical sources (including the Getty Research Institute database) for different phases of Western art [3,5-8]. Competitive conditions on the demand side are found in each of these markets according to basic economic tests, for instance for the "law of one price" of sales across different destinations [5-8]. Finally, we have collected complete data on the top prices of artworks traded in contemporary auctions worldwide (from the Artnews's database), characterized by competitive bidding

The authors are grateful to Albert-Laszlo Barabási for comments and declare that they have no competing financial interests.

* Correspondence to: Ca' Foscari University, Venice, Sestiere Cannaregio, 30121, Fond.ta S. Giobbe 873, Venice, Italy.

E-mail address: federico.etro@unive.it (F. Etro). 
F. Etro, E. Stepanova / Physica A xx $(x x x x) x x x-x x x$
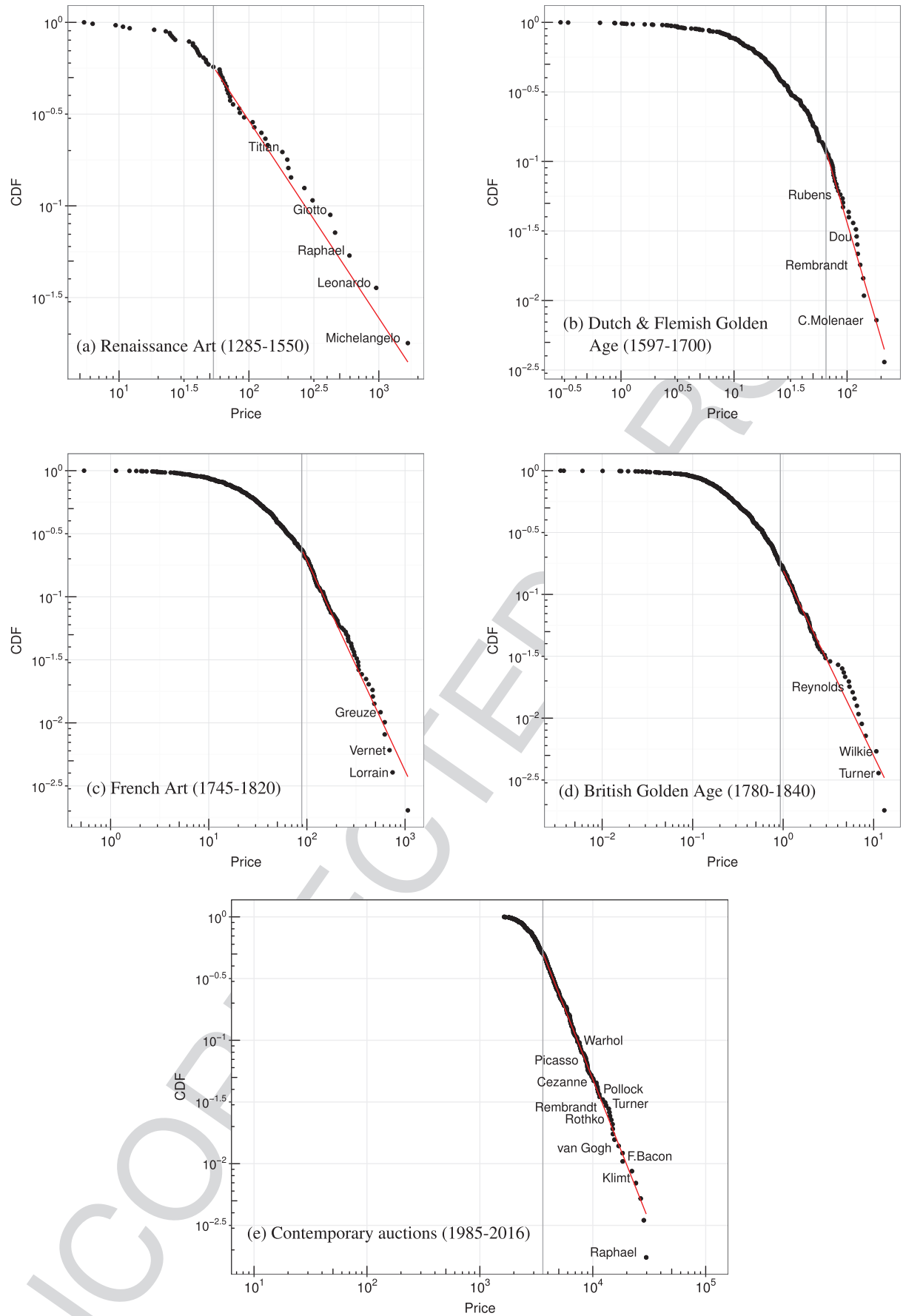

Fig. 1. Power-laws in art. Distribution of average prices (deflated for consumer price inflation) per artist (with multiple observations). The red line is the estimated Pareto tail for prices above $p_{m}$ (vertical gray line) with scale parameter $\alpha$ ( $p$-value for goodness-of-fit test from [1]: it supports the power law when significantly different from zero). (a) Prices in gold florins of 1285 for the primary market in Italy (56 artists): $\alpha=2.07 \pm 0.18$ with $p_{m}=53 \pm 30$ ( $p$-value 0.53). (b) Prices in guilders of 1597 for estimates in Amsterdam inventories ( 277 Dutch and Flemish artists): $\alpha=3.77 \pm 0.81$ with $p_{m}=65 \pm 17$ ( $p$-value 0.21). (c) Prices in livres of 1745 for Paris auctions (494 French painters): $\alpha=2.67 \pm 0.25$ with $p_{m}=87 \pm 18$ ( $p$-value 0.75 ). (d) Prices in pounds of 1780 for Christie's auctions in London (556 British painters): $\alpha=2.50 \pm 0.25$ with $p_{m}=0.9 \pm 0.2$ ( $p$-value 0.55 ). (e) Prices in thousand dollars of 2010 for global auctions ( 575 artists from any period of painting and sculpture and any provenance in the world): $\alpha=3.31 \pm 0.22$ with $p_{m}=3612 \pm 680$ ( $p$-value 0.41). The datasets and the consumer price inflation used for (a)-(d) are described and analyzed further in [5-8]. (For interpretation of the references to color in this figure legend, the reader is referred to the web version of this article.)

and maximum information spreading. On this basis we have studied the distribution of the average price per artist, corrected for consumer price inflation. 


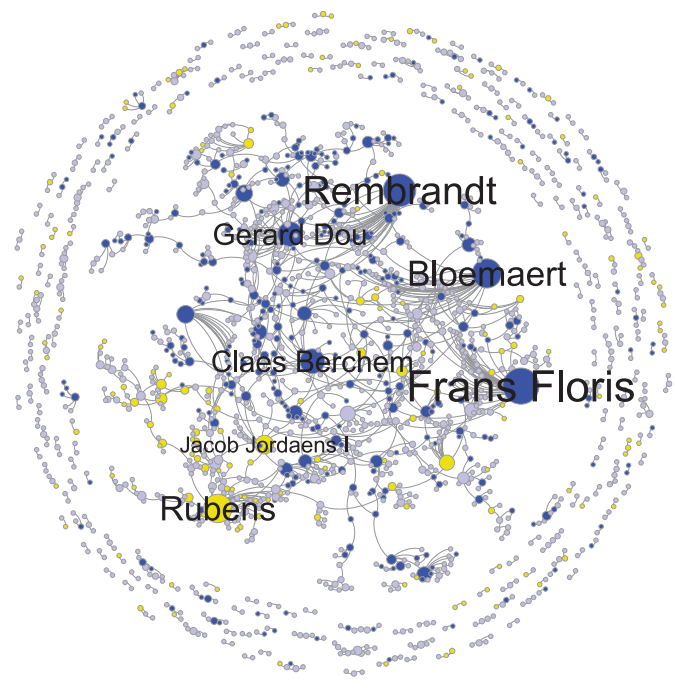

(a)

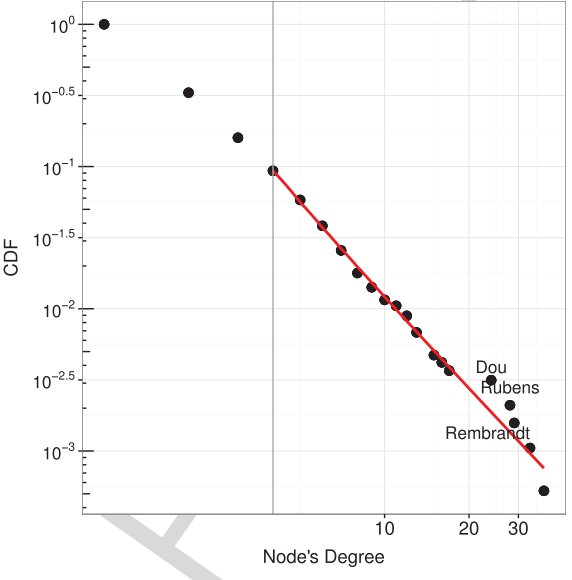

(b)

Fig. 2. Master-student network of Dutch and Flemish artists (1500-1700). (a) Network of masters and students. Our elaboration on data from Ecartico. The size of nodes increases with the number of degrees (students). Identified Dutch painters are in blue and Flemish painters in yellow. (b) Scale-free distribution of the number of students per master: scale parameter $\gamma=3.06 \pm 0.3$ with lower bound $k_{m}=4 \pm 1$ ( $p$-value for goodness-of-fit test 0.65 , supporting the power-law). (For interpretation of the references to color in this figure legend, the reader is referred to the web version of this article.)

Fig. 1 presents the results in log-log diagrams, showing a power-law tail in all cases, with a density

$$
\operatorname{Pr}(p) \sim p^{-\alpha}
$$

for the price $p$, and a scaling parameter $\alpha$ around three. We follow standard methods [1] in estimating this parameter and the lower bound of the scale-free distribution, and test successfully for the latter in all cases. Notice that this pattern is consistent with variability of prices with quantifiable characteristics of the commissions (such as size, number of figures depicted, support of the painting or the same age of the painter) emerging from hedonic regressions controlling for artists' fixed effects [4,5]: even if the distribution of individual talent (average price per painter) follows a power-law, the value of individual paintings can change across different commissions and along the career of a painter.

Artistic talent is the ability to innovate in the production of valuable handmade objects. All innovations are more likely to emerge in an appropriate environment [9], and artistic innovations flourished in Renaissance Italy thanks to a combination of facilitating factors: economic prosperity leading to accumulation of non-productive capital, well-ruled city-states, a dynamic upper-class looking for social recognition through its purchases, and a well functioning primary market that could reward and price artistic quality. We have collected the first dataset of prices of paintings (in gold florins) sold by Italian masters to public and private commissioners between 1285 and 1550 (for 315 documented transactions from art historical sources) [5]. Fig. 1(a) shows the distribution of the average price per painter, whose tail follows a power law with exponent $\alpha \approx 2.1$. The birth of extraordinary talents such as Leonardo, Michelangelo and Raphael in a short period of time, which appears inconsistent with a normal distribution of talent around a characteristic scale, is entirely consistent with such a scale-free distribution: once the demand for paintings increased and attracted new artists in the profession, unprecedented talents emerged rather frequently, and spread their innovations (such as perspective, oil colors or their personal style) through their followers.

We find a power-law tail also in Fig. 1(b), where we plot the same distribution based on Dutch and Flemish paintings found in Amsterdam's inventories during the 1600s (this dataset includes 2300 observations) [3,6]. Here the scale parameter is $\alpha \approx 3.8$, reflecting higher concentration on artists with lower average prices, as we should expect for what was the first mass market in art history [3]. This pattern can also help to explain the evolution of artistic talent by looking at the relation between masters and apprentices: the network of teachers-students forms a tree which we have reconstructed for Dutch and Flemish painters active over two centuries, with 1906 nodes and a giant component including 60\% of the links (Fig. 2(a)). We found that this is a scale-free network (Fig. 2(b)) where the probability of each master having $k$ students follows:

$$
\operatorname{Pr}(k) \sim k^{-\gamma}
$$

with $\gamma \approx 3$ : masters such as Rembrandt or Rubens were not only better paid, but they had also more students, than ordinary painters. Applying theories of dynamic networks [10,11] and mentorship [12] we can replicate such a scale-free network and the positive correlation between average price of teachers and number of students $(0.61)$ just by assuming that the choice of 
a teacher was based for each new painter on (a weighted average of) preferential attachment [10] and relative "fitness" [11] proxied by the average price of the active painters. This can explain how more talented painters attracted and trained more followers spreading their art within artistic schools and genres: the correlation between average prices of teachers and their students is indeed positive (0.15).

Since the 1700s and 1800s art auctions flourished in larger centers as Paris and London, where new elements of a modern efficient art market emerged: first a network of art dealers in Paris [7] and then art investment as an additional form of financial diversification in London [8]. These markets provides us with wider dataset for our tests. In Fig. 1(c)-(d) we obtain power-laws with scale parameters $\alpha \approx 2.7$ and $\alpha \approx 2.5$ respectively for French and British painters (each dataset includes about ten thousand observations on painters active in the domestic market).

Our last test for a power-law of art pricing is on contemporary data from a globalized market. In Fig. 1(e) we use data on the top 10,000 prices of any artwork traded in any contemporary auction worldwide in the last thirty years. Also in this case the power-law in the tail is extremely evident, and statistically supported, with a scale parameter $\alpha \approx 3$.3. Superstars include those from earlier schools as well as contemporary artists, for instance impressionists and post-impressionists (Cezanne and van Gogh) or abstract expressionists (Pollock and Rothko). In conclusion, the persistence over many centuries and across heterogeneous markets of what appears as an approximately cubic law of art pricing hints to a general pattern for the distribution of artistic talent.

\section{References}

[1] A. Clauset, C.R. Shalizi, M.E.J. Newman, Power-law distributions in empirical data, SIAM Rev. 51 (4) (2009) 661-703.

[2] X. Gabaix, Power laws in economics and finance, Annu. Rev. Econ. 1 (1) (2009) 255-294.

[3] J. Montias, Art at Auction in 17th-Century Amsterdam, Amsterdam University Press, Amsterdam, 2002.

[4] D. Galenson, Painting Outside the Lines, Harvard University Press, Cambridge, 2002.

[5] F. Etro, The economics of Renaissance art, J. Econom. Hist. 78 (2) (2018) 1-39.

[6] F. Etro, E. Stepanova, Entry of painters in the Amsterdam market of the golden age, J. Evol. Econ. 26 (2) (2016) 317-348

[7] F. Etro, E. Stepanova, The market for paintings in Paris between Rococo and Romanticism, Kyklos 68 (1) (2015) $28-50$.

[8] F. Etro, E. Stepanova, Art auctions and art investment in British painting at the time of the industrial revolution, Scottish J. Political Econ. 64 (2) (2017) $191-225$.

[9] J. Diamond, Guns, Germs, and Steel, Norton, New York, 1997.

[10] A.-L. Barabási, R. Albert, Emergence of scaling in random networks, Science 286 (5439) (1999) 509-512.

[11] G. Bianconi, A.-L. Barabási, Competition and multiscaling in evolving networks, Europhys. Lett. 54 (4) (2001) 436.

[12] R.D. Malgrem, J.M. Ottino, L.A.N. Amaral, The role of mentorship in protégé performance, Nature 465 (7298) (2010) $622-626$. 